\title{
Causes, Consequences and Prevention of Refrigeration Fires in Residential Dwellings
}

\author{
M.G. Beasley ${ }^{1}$, P.G. Holborn², J.M. Ingram², G.G. Maidment ${ }^{3}$ \\ ${ }^{1}$ London Fire Brigade, 94-95 Upper Thames Street, London, EC4R 3UE \\ ${ }^{2}$ Explosion \& Fire Research, London South Bank University, London, SE1 OAA. \\ ${ }^{3}$ Centre for Air Conditioning and Refrigeration Research, London South Bank University, \\ London, SE1 OAA.
}

\begin{abstract}
There are around 300 residential dwelling fires in Great Britain each year where a fridge or freezer is cited as the cause. A number of these incidents have resulted in injuries/fatalities and produced significant levels of property damage. This paper examines the causes and consequences of refrigeration fires in residential dwelling fires in Great Britain (London and England) and the evidence collected via fire investigation of residential dwelling fires involving fridges or freezers. Analysis of the data collected from these fires suggests that, once ignition occurs, fires started by faults in fridge/freezers are more likely to spread beyond both the appliance and the room of origin, and tend to cause more damage than fires started by the other types of white goods appliance (washing machine, dishwasher or tumble dryer). A number of common failure modes leading to ignition in domestic refrigeration fires, along with specific fire escalation and spread mechanism are identified. Based upon the information obtained from fire investigations and a comparison between the design and construction of refrigeration appliances used in Great Britain and USA, a number of recommendations are suggested which could be used to help reduce the risk of domestic refrigeration fires.
\end{abstract}

\section{Introduction}

Over the past decade around 300 domestic fires in Great Britain have occurred each year, where the cause was found to be a fridge or freezer [1]. A number of these incidents have resulted in injuries/fatalities and produced significant levels of property damage. For example, in September 2011, 6 people died and 2 were injured in a serious fire caused by a freezer that badly damaged the ground and first floor of a two storey semi-detached house in Neasden, London, UK [2]. A fridge-freezer is also suspected to be a possible initial cause of the Grenfell Tower fire [3], which resulted in massive loss of life and catastrophic structural damage, occurring in a high-rise residential tower block in London, UK, in June 2017.

Moreover, in recent years, whilst the overall number of fires in residential dwellings in London has been falling (e.g. down by 13\% over the 5 years from 2011 to 2015), fires started by fridges and freezers, along with other types of faulty "white goods" appliances (i.e. washing machines, tumble dryers and dishwashers) represent a persistent source of fires in the home, that has not followed this downward trend [4]. 
It is therefore extremely important to analyse such incidents to examine their characteristics and understand the underlying ignition and fire spread mechanisms that have led these fires to occur and how they might be mitigated. However, despite the ubiquity of domestic refrigerators, relatively few studies have been made of the characteristics, causes and consequences of fires involving such systems in residential dwellings.

Hall [5] has examined home structure fires, in the US, involving kitchen equipment (other than cooking equipment) that occurred between 2006 and 2010. The majority of these fires (59\%) involved refrigerators (or separate freezers and ice makers). On average, 1,710 of these fires occurred each year, producing 2 fatalities, 56 injuries and $\$ 50$ million in direct property damage per year. The majority (66\%) of these fires started in the kitchen. Most of the incidents involving refrigerators or freezers were attributed to electrical or mechanical failures or malfunctions - but there were few details, if any, available on the nature of the failure or malfunction that contributed to ignition.

Yang et al. [6] outlined a methodology which has been employed, in China, to investigate fires caused by a household refrigerator (similar in nature to the one used by London Fire Brigade fire investigators). The method considers the material evidence (smoke and burning traces): (i) around the refrigerator; (ii) in the refrigerator; (iii) the power supply, cables and plug boards; and (iv) switches and relays. They discuss how the analysis of fire traces smoke and burn patterns imprinted on surrounding surfaces and objects as the fire develops and wires melted by the fire can (providing the level of damage is not too severe) be applied to find the direction of fire spread, identify the area of fire origin and hence determine the probable cause of the fire (for further details on the use of fire patterns and their interpretation for complex geometries close to walls, under counters etc. see [7-9]).

Hietaniemi et al. [10] carried out an experimental study, at the VTT large fire test facility in Finland, to examine the burning characteristics (heat release rate, smoke generation) of four different types of electrical household appliance - including four tests performed on fridgefreezers. Two of the fridge-freezers tested were left freestanding, whilst the other two were located in cupboards to try to replicate the conditions of a typical domestic mounting. They found that the fridge-freezer fires exhibited by far the highest peak heat release rate of all the appliances tested $-2000 \mathrm{~kW}$. These tests also had to be interrupted and extinguished because the fire grew so large it could have damaged the experimental test rig. It is therefore likely that the actual peak heat release rate, had this not occurred, would have been in excess of $2000 \mathrm{~kW}$. On the basis of these test results, they concluded that such high rates of heat release would produce a very high burning rate in a room the size of a kitchen and that consequently there would be a high likelihood of flashover occurring (although ventilation, fire growth rate etc. will also impact the likelihood of flashover [11] and introduce additional uncertainties that need to be taken into consideration). The origin of the high heat release rates observed in the tests were attributed to the considerable quantities of plastic used (polyurethane foam insulation, along with polypropylene and polystyrene) in the construction of the fridge-freezers tested and the nature of the design of the appliance (vertical cabinet), producing a chimney like flue, which significantly enhanced flame spread and burning behaviour. 
Beard and Goebelbecker [12] describe some fire tests that were carried out for EFRA (European Flame Retardants Association) on a range of household appliances, including a single refrigerator unit. The unit had steel covers on the front and sides with an interior constructed from plastics - polystyrene (PS), polyurethane (PUR) insulation and polypropylene (PP). The refrigerator was ignited using an IEC TS 62441 needle flame. The fire was allowed to burn, without any suppression being applied, for over 30 minutes. The peak heat release rate measured during the fire test was $852 \mathrm{~kW}$. On the basis of the tests, they concluded that small flame ignition sources could pose a definite risk to household appliances like refrigerators.

Such studies have highlighted the potential importance of refrigeration fires and the very high heat release rates that they can generate. There is therefore a need for a more general study to examine the causes, consequences and prevention of refrigeration fires in residential dwellings. Herein, data collected for residential dwelling fires caused by faults in fridge/freezers in London (2011-2015) and England (2010/11 to 2015/16) have been analysed to identify the likelihood and consequences of fridge/freezer fires and fires caused by other comparable types of domestic "white goods" appliance (washing machines, dishwashers and tumble dryers). Note that in the data analysis that follows the generic term fridge/freezer is adopted to denote the aggregate of fires caused by refrigerators, freezers and combined fridge-freezer units taken together. An examination of evidence collected via fire investigation of residential dwelling fires in London, where faults in fridges/freezers have been identified as the source of ignition, has also been made. On the basis of this work a number of generic failure modes leading to ignition and fire spread in fridge/freezers have been identified. The generic reasons for the cause and spread of the fire and potential ways of constructing fridge/freezers that could be used to reduce the risk, spread and consequences of these fires are also examined.

\section{Method}

\section{I Information from Fire investigation}

London Fire Brigade (LFB) attends around $10 \%$ of all the fires in the UK [13] and around $20 \%$ of the recorded appliance fires. LFB first set up a dedicated fire investigation team in 1983. Since that time specialist fire investigation officers have been available to assist the incident commander in determining the origin and cause of a fire. LFB fire investigators attend the most significant and severe fire incidents, and are required to attend any fire incident involving an injury, fatality or where the cause of the fire is unknown.

The range and usefulness of the data collected by LFB fire investigators was originally recognised during the mid-1990s, which led to the creation of a Real Fire Library (RFL) database. This was used to organise and store the information collected from LFB fire investigations, until 2008, when it was superseded by the Incident Information Management System (IMS). The data collected into the RFL has also formed the basis of a number of research studies into fire safety [14-16]. 
Part of the research also involved regular visits to local authority re-cycling yards where permission had been given to examine refrigeration appliances. The condition of a number of appliances - e.g. defrost switches were examined and recorded and used to provide additional insight into possible ignition mechanisms.

\subsection{Fire data analysis}

In order to determine the likelihood and consequences of fires caused by faults/defects occurring in domestic refrigeration systems (refrigerators, freezers and fridge-freezers) in residential dwellings and allow a comparison to be made with fires caused by other types of domestic "white goods" appliances (dishwashers, washing machines and tumble dryers) the following data sets have been used:

(i) DS-1: London Fire Brigade IMS data for appliance fires in London 2011-2015

London Fire Brigade (LFB) record data about the fires they attend into the LFB Incident Management System (IMS). The IMS meets the requirements specified for the UK government's national Incident Recording System (IRS), which LFB adopted in 2008.

The IMS data set used for the study contains data recorded about the appliance fires, attended in Greater London by LFB, over the five year period from 2011 to 2015. The analysis was restricted to "white goods" appliance fires involving - fridge/freezers, dishwashers, washing machines and tumble dryers - that occurred in residential dwellings, where the main cause of the fire was determined to be a "fault in equipment or appliance". This data set includes a field "At Stop Damage Spread Size" which groups the level of fire damage at the point the fire was stopped into several different categories. Using this data it is possible to determine the number (and percentage) of fires that spread beyond both the first item ignited and the first room and hence provide a simple measure of the level of damage caused by each type of appliance fire.

(ii) DS-2: Home Office IRS Incident level domestic appliance fires data set for England (and London) $2010 / 11$ to $2015 / 16$

This (incident level) data set issued by the UK government (Home Office) is for primary dwelling (i.e. residential household) fires recorded into the Incident Recording System in England, where the ignition source was identified as a domestic appliance [17]. The data collected is based on financial years running from 1st April to 31st March running from 2010/11 onwards over a six year period. The analysis performed here was restricted to a subset of appliance fire incidents involving fridge/freezers, dishwashers, washing machines and tumble dryers, where the cause of the fire was determined to be "faulty appliances and leads". This data set also allows subsets of incidents for specific regions, including London, to be selected for analysis. The fire data set for England (DS-2) also includes the field "FIRE_DAMAGE_EXTENT". This provides a measure of the total horizontal area damaged by the flame and/or heat (in $\mathrm{m}^{2}$ ) at the stop of the fire and is divided into ten different categories (0, Up to 5, 6 to 10, 11 to 20,21 to 50, 51 to 100, 101 to 200, 201 to 500, 501 to 1000, Over 1000). 
Whilst the fire data can provide information on the number of fires caused by each type of appliance, in order to quantify the relative likelihood of fire occurring (i.e. the probability of a fire) a measure of the number of appliances in use must also be taken into account. In order to do this (for both London and for England) data obtained by the UK Office for National Statistics (ONS) - "percentage of households with durable goods by UK countries and regions, 2012 to 2014" has been used [18]. This data set provides estimates of the percentage of households in the UK (including England as a whole and for individual regions, including London) having different types of appliances (including fridge/freezer, dishwasher, washing machine and tumble dryer) from which the number of households with each type of appliance can be derived. The data set used is based upon a selected sample survey of households in Great Britain. Like all estimates based on samples, the results of the sample survey data for percentage of households durable goods are subject to sampling errors and data entry errors. It is used herein to provide a comparative measure of estimated number of appliances of each type of white goods appliance.

\section{Causes}

\section{I Likelihood of fire}

Table 1 provides a comparison of both the number and annual probability of occurrence of fridge/freezer fires in London (DS-1) with those observed for the other types of domestic "white goods" appliance - washing machines, dishwashers and tumble dryers (along with the estimated percentage and number of households having that appliance). The results suggest that fridge/freezers exhibited the lowest probability of fire occurrence $\left(1.5 \times 10^{-5}\right.$ per year) - around half that found for both dishwashers and tumble dryers $\left(3.1 \times 10^{-5}\right.$ per year). Note also that fridge/freezers tend to be on continuously, whereas the other white goods are generally only used periodically over the week, for much shorter time periods. Taking usage time into account would further shift the balance in the direction of fridge/freezers having the lowest likelihood of fire occurrence.

\begin{tabular}{|c|c|c|c|c|}
\hline Ignition Source & Fires $^{1}$ & $\begin{array}{c}\% \text { Households } \\
\text { with appliance }\end{array}$ & $\begin{array}{c}\text { Households } \\
\text { with appliance }\end{array}$ & $\begin{array}{c}\text { Probability of fire } \\
\text { (per year) }^{3}\end{array}$ \\
\hline Dishwasher & 206 & $41 \%$ & $1,320,200$ & $3.1 \times 10^{-5}$ \\
\hline Tumble Dryer & 208 & $42 \%$ & $1,352,400$ & $3.1 \times 10^{-5}$ \\
\hline Washing Machine & 387 & $97 \%$ & $3,123,400$ & $2.5 \times 10^{-5}$ \\
\hline Fridge/Freezer & 230 & $97 \%$ & $3,123,400$ & $1.5 \times 10^{-5}$ \\
\hline
\end{tabular}

${ }^{1}$ Based on DS-1: Appliance fires in residential dwellings in London, 2011-2015, where the cause was attributed to a fault in the appliance.

${ }^{2}$ Based upon data for London from ONS Family Spending 2015 - Table A48: Percentage of households with durable goods by UK countries and regions, 2012 to 2014 [14].

${ }^{3}$ Estimate assumes one appliance per household.

Table 1. Estimated annual probability of fire by, white goods appliance type, for residential dwellings in London (DS-1). 


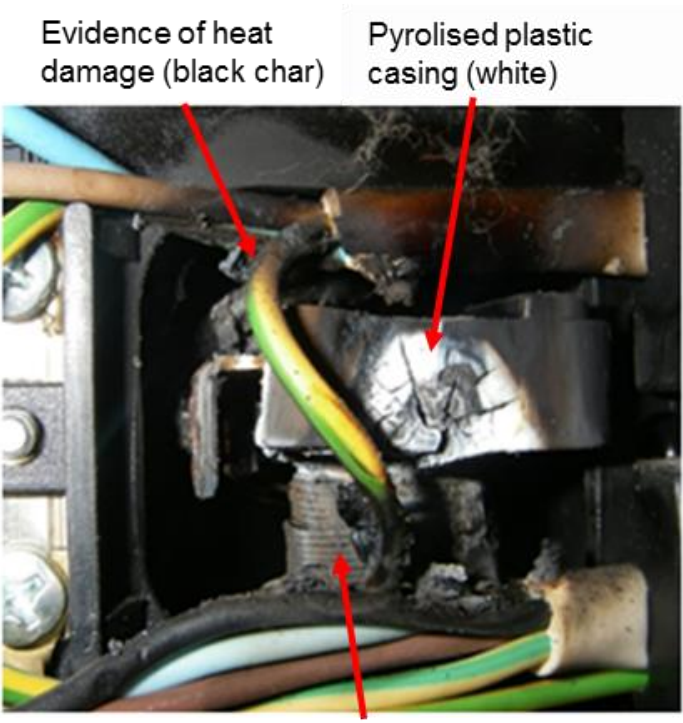

(a) Overheated starter coil (deformed)

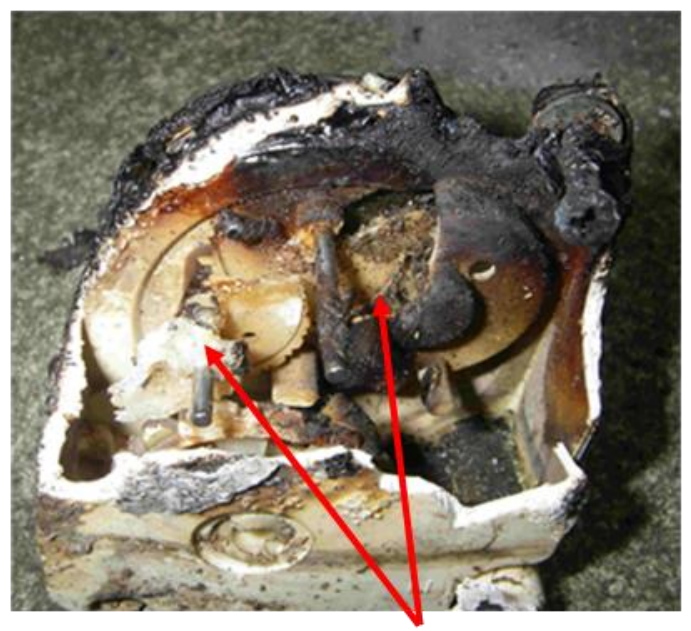

(c)
Plastic cogs (melted/charred)

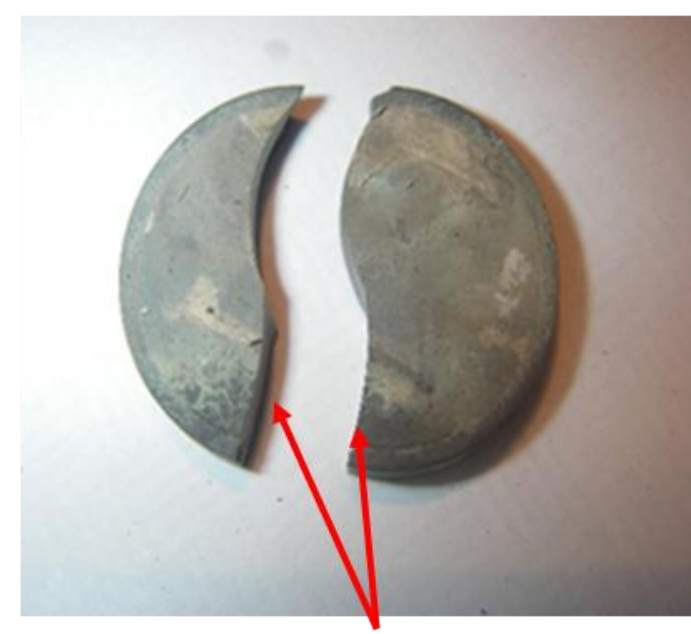

(b) Fracture with smooth edges

Exposed burnt interior material

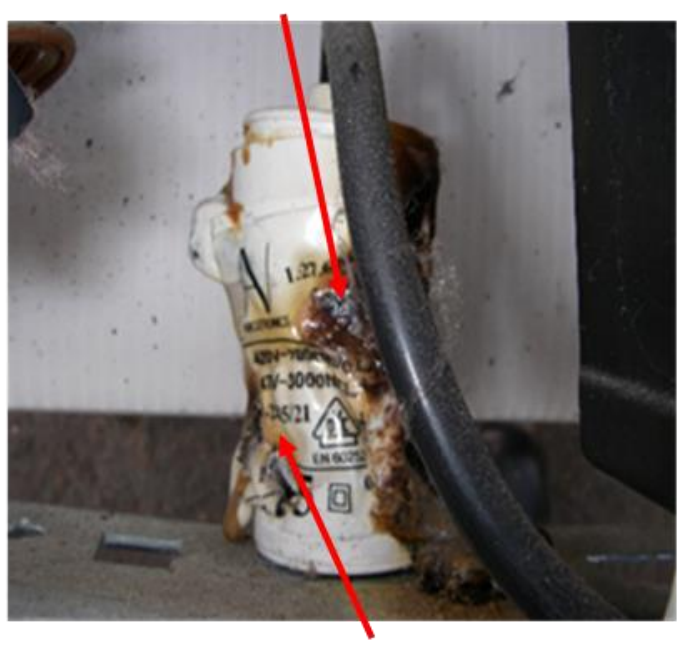

(d)

Fig 1. Some examples of ignition sources observed in refrigeration appliance fires: (a) starter relay failure; (b) PTC pill failure; (c) mechanical defrost switch failure; (d) capacitor failure.

\subsection{Failure modes leading to ignition}

Based upon an analysis of LFB fire investigation of a large number of incidents the following common failure mechanisms leading to ignition in domestic refrigeration fires (see Fig. 1) have been identified: 


\subsection{Starter relays}

Earlier models of fridge/freezer employ a starter relay attached to the compressor. This allows current to pass to the start windings of the compressor. Once the compressor starts to run, the relay opens, cutting off the current, and the compressor then functions independently. Breakdown of the windings of the start relay coil results in severe heating to the coil assembly and external heat damage to the body of the switch and the adjoining cabling (Fig. 1(a)). This failure mechanism has been recorded for many years. Since the switch to PTC starters the number of incidents together with the often limited amount of resulting damage means this fire cause is now less common and in decline.

\subsubsection{PTC starter switches}

The starter switch is used to start the operation of the compressor motor. It normally consists of a PTCR (positive temperature coefficient of resistivity) ceramic "pill" housed in a plastic body containing the electrical connections. The barium titanate ceramic material used in the pill undergoes a sharp transition from a low resistance (semiconductor) to a high resistance (insulator) state above a critical temperature (typically around $120^{\circ} \mathrm{C}$ ). Hence the pill functions as a temperature switch.

Arcing between the metal contacts positioned either side of the pill can occur due to: electrical breakdown of the pill's ceramic material, characterised by cracking and fracturing of the pill, forming smooth surfaces [19] - see Fig 1(b) - or via a conductive path of adipic acid being formed on the surface edges of the pill over time, through the breakdown of nylon present in the adjacent plastic cover material. This electrical arcing can then lead to heating and degradation of the switches' wiring and plastic cover material, resulting in pyrolysis and the release of flammable gases. The flammable gases released can then be ignited by the electrical arcing, resulting in a flaming ignition source being generated.

\subsubsection{Mechanical defrost switch failures}

The defrost switch timer is used to switch the refrigeration appliance between cooling and defrost cycles, allowing the evaporator coils to be automatically defrosted. Under some circumstances, water can collect inside the appliance housing (e.g. as a result of the drain tube running from the refrigerator to the drip tray becoming detached) and then penetrate into the defrost switch casing. Here it can form a conductive path between defrost switch contacts resulting in arcing and heating of the interior of the switch case. This heating produces degradation and pyrolysis of the plastic components (e.g. cogs) located within the switch (Fig. 1(c)), which have a high nylon content, leading to the release of flammable gas vapour which can accumulate in the case. This can then be ignited by the electrical arcing, resulting in a flaming ignition source. This behaviour has been found across a number of different defrost switch types. 


\subsubsection{Capacitor failures}

Capacitors have been fitted to almost all modern refrigeration appliances since around the year 2000. Positioned within the compressor compartment located at the base of the refrigeration appliance, its function is normally to either provide a start or run facility which smooths out electrical supply imbalances to the compressor. It is usually located to the left of the compressor, although it may also be found mounted adjacent to the compressor start switch. During its lifetime the capacitor will be subjected to various types of stress which can cause it to age and eventually fail, including: over-voltages, over-heating, pollution, humidity, radiation, and vibrations. A capacitor failure can range from a simple failure of its circuitry, leading to a slow melting and degrading to form char, to a dramatic and violent ignition or pressurised eruption (Fig 1(d)).

\subsubsection{Solenoid valve failures}

The solenoid valve is used to control the flow of refrigerants and switching of refrigerant between either the refrigerator or freezer compartments. It consists of a small electrical coil, which when activated produces a magnetic field, which then draws up an iron/steel plunger into the body of the solenoid. A pin (with a surrounding seal) attached to the end of the plunger is then raised thereby opening a valve port allowing the refrigerant to flow. In some cases, the solenoid valve can fail, due to increasing electrical resistance and breakdown of the electrical coils over time, leading to heating of the solenoid unit. This heating can then cause the seal to the refrigerant to become degraded and compromised to point where it can allow flammable refrigerant gas (e.g. R600a) to escape and be ignited by a spark from the failed electrical coil or an adjacent PTC switch.

\subsubsection{Cut-out switch failure in integrated appliances}

Many of the fridge/freezer fires examined over the last three decades have occurred in integrated units that have been in place for over 20 years, and can be traced to the failure of both a ventilation cooling fan and a bi-metallic cut-out switch. In the case of an integrated appliance the fridge/freezer is built into the kitchen units. A plastic base tray houses the compressor and associated wiring, together with a fan ventilation/cooling system. With natural airflow restricted, the cooling is provided by an electric powered fan providing blown air to the condenser coils. Fan failure can occur when a build-up of fluff, hair or other debris collects within the base area, drawn into the fan from the kitchen. The failure of the cooling fan results in the integrated fridge/freezer unit receiving insufficient cooling via external airflow and requires the repeated operation of a thermal cut-out switch to prevent overheating. The continuous on/off cycling of these kinds of switches, can lead to arcing behaviour and ignition, either directly through the erosion of the switch contacts, caused by repeated arcing as the switch is repeatedly turned on and off, or via a mechanism known as arc tracking (carbon tracking).

In arc tracking, small leakage currents can form on the surface of the nonconductive insulation materials present in the switch due to the presence of contaminants (e.g. salts, conductive dusts, or liquids). Such small currents can produce heating, resulting in 
degradation of the surrounding insulation material and the formation of carbon-char, which is an electrical semi-conductor. This in turn can lead to greater current flow, via the alternate conduction path formed, resulting in further heating and further accelerating the production of carbon. Such a process can often occur over extended times, at a slow rate, with the current progressively increasing, until a point is reached where arcing through the carbonised char may occur, resulting in ignition of the carbonised insulation supporting the switch contacts (for further details see [7] pg. 108, and [8] pg. 329).

\section{Consequences}

\section{I Casualty rate}

Table 2 provides a breakdown (using DS-1) of the number of fires, injuries and fatalities (and the casualty rate per 1000 fires) for each of the different types of "white goods" appliance that occurred in residential dwellings in London 2011-2015 (where the cause was attributed to a fault in the appliance). An injury is classified as a person requiring hospital treatment (both slight and severe), first aid treatment or a precautionary check-up. Fridge/freezers were responsible for the largest number of fire related injuries - significantly more than for the other types of appliance examined - whilst washing machines were found to be responsible for relatively few injuries - despite having the highest incidence of fire. Fridge/freezers were also the only type of appliance to be responsible for causing fire related fatalities ( 8 deaths) during the period considered.

\begin{tabular}{lcccc}
\hline Ignition Source & Fires & Injuries & Fatalities & $\begin{array}{c}\text { Casualty rate } \\
\text { (per 1000 fires) }\end{array}$ \\
\hline Fridge/Freezer & 230 & 69 & 8 & 335 \\
Dishwasher & 206 & 46 & 0 & 223 \\
Tumble Dryer & 208 & 37 & 0 & 178 \\
Washing Machine & 387 & 13 & 0 & 34 \\
& & & & \\
\hline
\end{tabular}

Based on DS-1: Appliance fires in residential dwellings in London, 2011-2015, where the cause was attributed to a fault in the appliance.

Table 2. The number of fires, injuries, fatalities and casualty rate, by white goods appliance type, for residential dwellings in London (DS-1). 


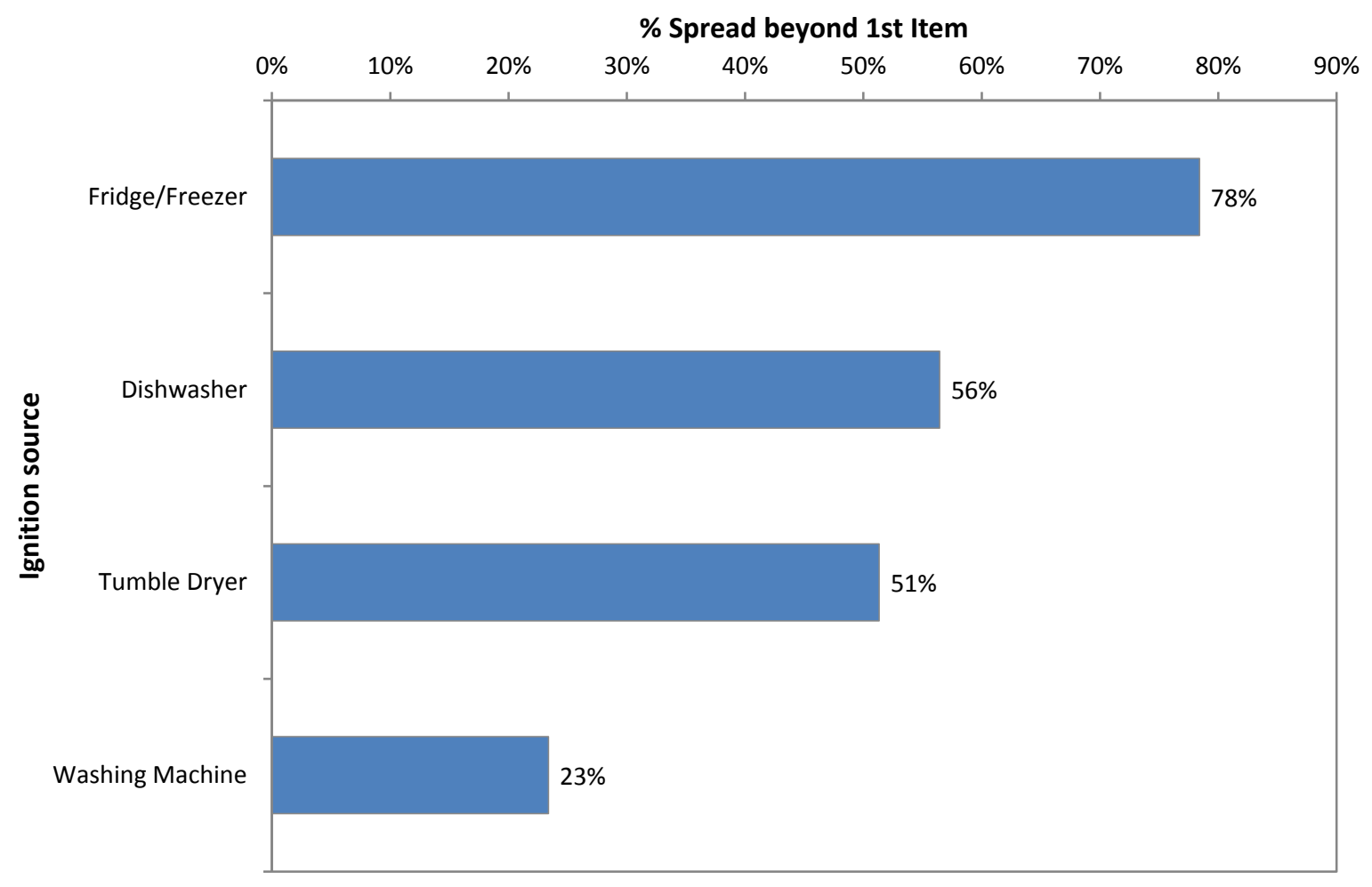

Fig 2. The different appliance types ranked in accordance with the percentage of fires spreading beyond the first item ignited in London (DS-1).

\subsection{Fire spread}

Fig. 2 shows the different appliance types ranked in accordance with the percentage of fires spreading beyond the first item ignited (DS-1). It can be seen that the majority of fridge/freezer fires (78\%) spread beyond the first item. Around half of the dishwasher (56\%) and tumble dryer (51\%) fires spread beyond the first item. In contrast less than a quarter $(23 \%)$ of the washing machine fires spread beyond the first item. 


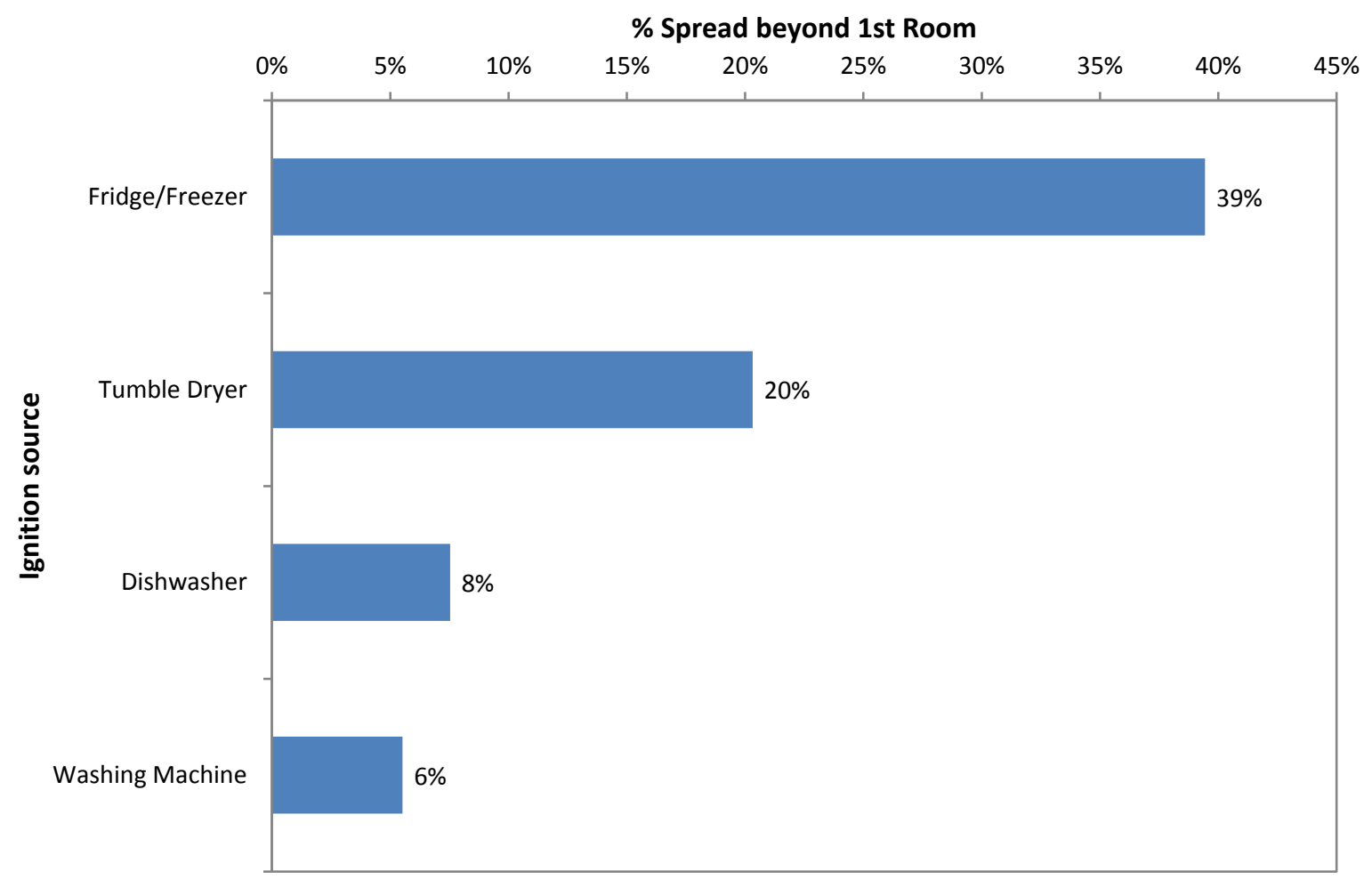

Fig 3. The different appliance types ranked in accordance with the percentage of fires spreading beyond the first room in London (DS-1).

Fig. 3 shows the different appliance types ranked in accordance with the percentage of fires spreading beyond the first room (DS-1). Once again fridge/freezers are ranked highest with $39 \%$ of fires spreading beyond the room of origin. By contrast $20 \%$ of tumble dryer fires spread beyond the room of origin. Only a small proportion of the fires caused by dishwashers (8\%) and washing machines (6\%) spread beyond the first room.

\subsection{Fire damage area}

Fig. 4 shows the complimentary cumulative distribution function (CCDF) for fire damage area (DS-2) that is obtained for each type of appliance (the CCDF gives the probability of a fire exceeding a particular fire damage area - see, for example, Fullwood and Hall [20]). From this it is evident that fridge/freezer fires are most likely to exceed a given fire damage area, followed by tumble dryer, dishwasher and with washing machine fires being the least likely. 


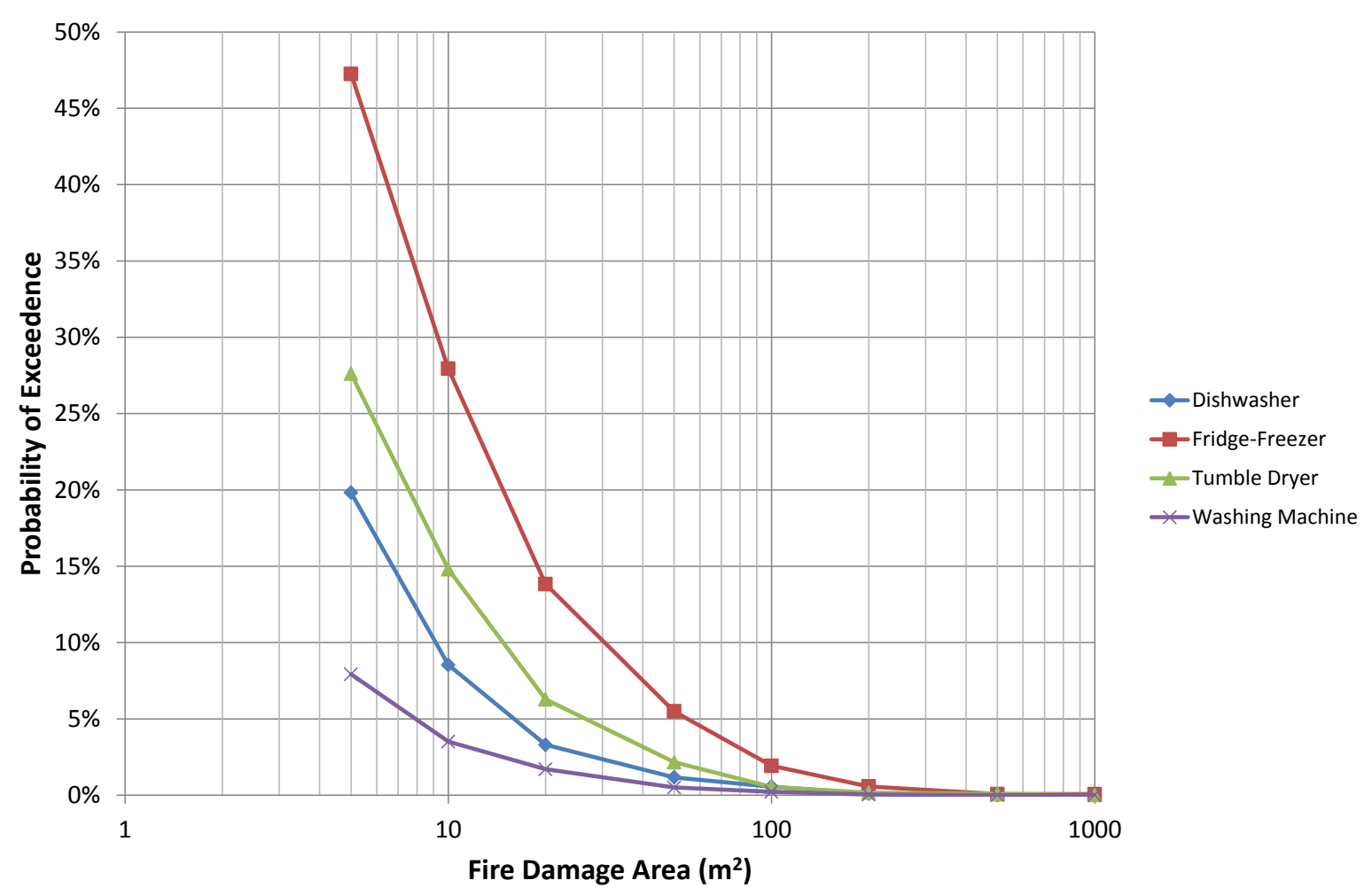

Fig 4. The CCDF for fire damage area, exhibited by different type of white goods appliance, for residential dwelling fires in England (DS-2). Each distribution gives the probability of fire damage exceeding a given area.

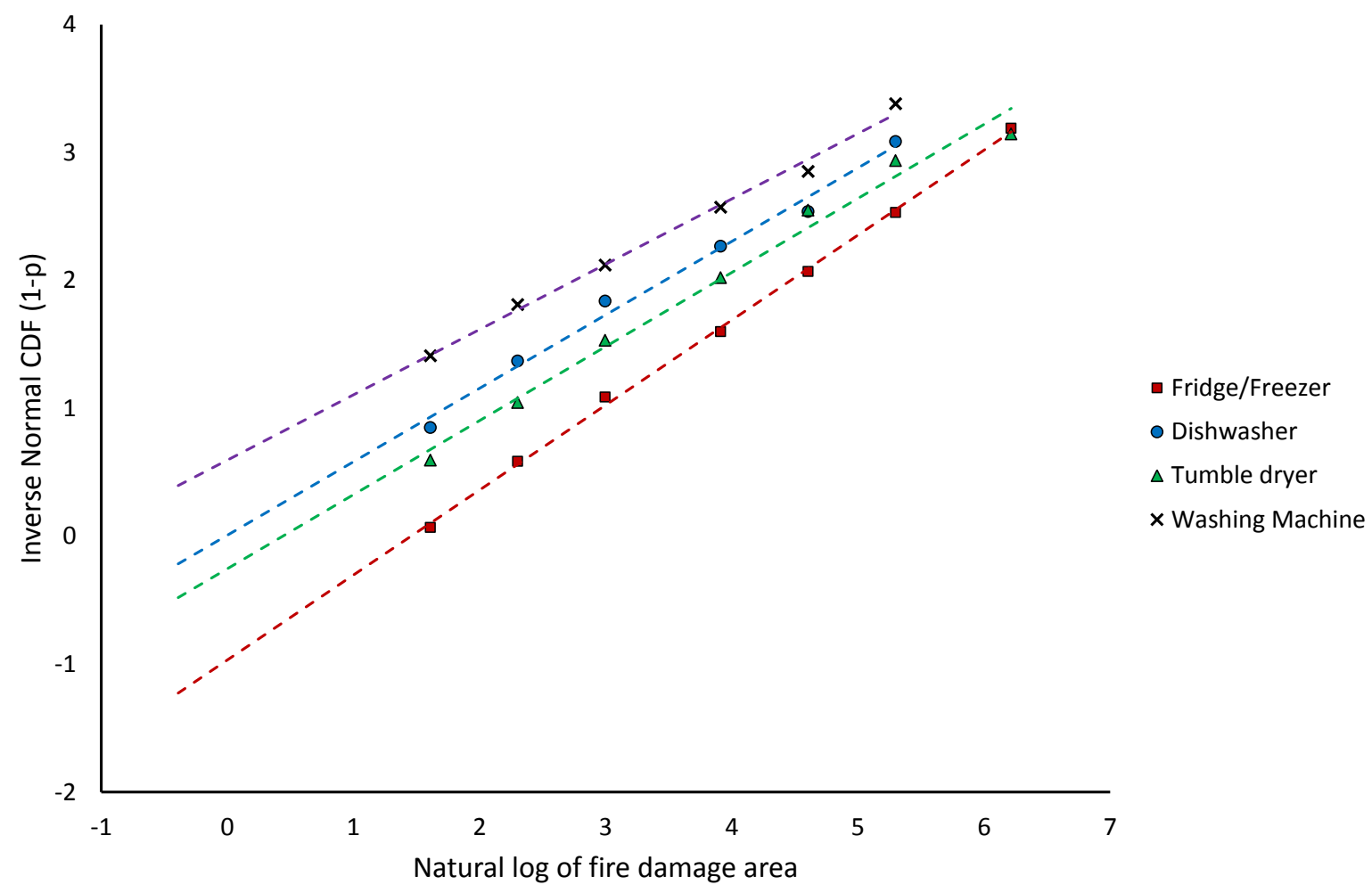

Fig 5. The linear regression lines fitted to the transformed CCDF fire damage area data for each type of white goods appliance. 
Previous research studies have shown that the statistical distribution of fire damage area is reasonably well approximated by the log-normal distribution [16, 21]. By assuming that the fire damage area, $x$, is log-normally distributed, a linear relationship between the inverse of the standard normal cumulative probability distribution, $\Phi^{-1}(y)$ and the natural log of the fire damage area, $z=\ln (x)$, can be obtained such that:

$$
z=\mu+\sigma \Phi^{-1}\left(1-p_{i}\right)
$$

Where, $\mu$ and $\sigma$ are respectively the mean and standard deviation of $z$, and $p_{i}$ are the cumulative probabilities plotted in the CCDF.

By applying this transformation to the CCDF fire damage area data for England (DS-2), linear regression can then be used to obtain $\mu$ and $\sigma$ and hence estimate the log-normal distribution parameters characterising the fire damage area for each type of appliance. Fig. 5 shows the resulting linear regression lines fitted to the CCDF fire damage area for each type of white goods appliance.

Using the properties of the log-normal distribution [16], it is also possible to calculate the expected value (i.e. the value of fire damage area most likely to occur) given by:

$$
E(x)=\exp \left(\mu+\frac{\sigma^{2}}{2}\right)
$$

the median value, given by:

$$
x_{50}=\exp (\mu)
$$

and a measure of the location of the tail of the distribution, indicated by the $95^{\text {th }}$ percentile, providing a single parameter measure of the largest value that will occur in $95 \%$ of cases, given by:

$$
x_{95}=\exp (\mu+1.645 \sigma)
$$

Table 3 summarises the corresponding fitted log-normal parameters characterising the distribution of fire damage areas, expected fire sizes and $x_{50}$ and $x_{95}$ values that are obtained for fires due to the different types of domestic appliance considered. The results suggest that fires caused by fridge/freezers tend to be responsible for higher levels of damage than is the case for fires started by the other types of "white goods" appliance. Thus, the expected fire size for fires due to fridge/freezers at $13 \mathrm{~m}^{2}$ is almost double that found for the next highest appliance type - tumble-dryers, as is the $x_{95}$ fire size of $51 \mathrm{~m}^{2}$. The results also again confirm the ranking order for "white goods" appliances, in terms of fire damage caused as being: fridge/freezer, tumble-dryer, dishwasher and washing machine. 


\begin{tabular}{|c|c|c|c|c|c|}
\hline \multirow[t]{2}{*}{ Source of ignition } & \multicolumn{5}{|c|}{ Estimated log-normal distribution parameters } \\
\hline & $\mu$ & $\sigma$ & $\mathrm{E}(x)\left(\mathbf{m}^{2}\right)$ & $x_{50}\left(\mathrm{~m}^{2}\right)$ & $x_{95}\left(\mathrm{~m}^{2}\right)$ \\
\hline Fridge/Freezer & 1.4576 & 1.5036 & 13.30 & 4.30 & 50.96 \\
\hline Tumble Dryer & 0.4909 & 1.7003 & 6.93 & 1.63 & 26.79 \\
\hline Dishwasher & 0.0219 & 1.7237 & 4.52 & 1.02 & 17.42 \\
\hline Washing machine & -1.1346 & 1.9462 & 2.14 & 0.32 & 7.90 \\
\hline
\end{tabular}

Based on DS-2: Appliance fires in residential dwellings in England, 2010/11-2015/16, where the cause was attributed to "faulty appliances and leads".

Table 3. Estimated log-normal parameters characterising the distribution of fire damage area in residential dwelling fires for different types of domestic appliance acting as source of ignition (based on fire data for England, DS-2).

\section{Escalation and fire spread mechanisms}

The results from the previous section suggest that once ignition occurs, fires in refrigeration appliances tend to produce higher severity consequences than the other types of white goods appliance. They are more likely to spread beyond the appliance and the room of origin and be responsible for causing higher levels of fire damage and casualties. Why do fires in fridge/freezer appear to escalate and spread more readily? Observations taken from LFB fire investigation would suggest that changes in fridge/freezer construction materials and design with time have resulted in a more flammable construction, where faults or failures are more likely to produce a significant fire. Based upon the results of these investigations, the following fire escalation and spread mechanisms have been identified:

\section{I. Plastic Drip Trays}

For many years, the evaporation tray housed on top of the compressor was made of thin metal. Its function was to retain any condensate water until it evaporated. However these trays would often rust and allow water to be displaced onto the compressor and the floor. The manufacturer's response was to replace the trays with plastic variants. The problem now is that the plastic drip tray provides an extensive flammable fuel source directly above compressor. There are a number of failure modes located in this region which can provide a flaming ignition source - e.g. PTC switch or capacitor failure - which can ignite the drip tray and further promote flame spread to other areas of the fridge-freezer (e.g. plastic backing material and interior PU insulation).

\subsection{Plastic and Cardboard Backing Materials}

The steel metal panels used, in older fridge/freezer designs, to cover the foam insulation at the back of the appliance, in the UK, have slowly been replaced in many appliance designs by a silvered cardboard or foil barrier covered by polyurethane or from the late 1990s onwards by a plastic polyethylene/polypropylene panel known as a "twin-wall". "Twin-wall" plastics are also often present as lining materials in the compressor compartment. 
Fire tests [22] have revealed that such plastic "twin-wall" and cardboard backing materials, when used in fridge/freezers, can become ignited very easily and then promote extremely rapid flame spread to involve insulation panels, whilst producing intense heat and large volumes of toxic smoke. A number of samples of rigid, C-pentane blown, polyurethane (PU) insulation foam together with materials typically used (as alternatives to steel) to cover the back panel of fridge/freezer appliances, in the UK, were obtained and tested. Table 4 summarises the characteristics of the different back panel samples that were examined. The different types of thin back panel covering material tested included several samples of "twin-wall" - polyethylene (PE) / polypropylene (PP) thermoplastic, along with other panels constructed from foil/cardboard and ABS plastic.

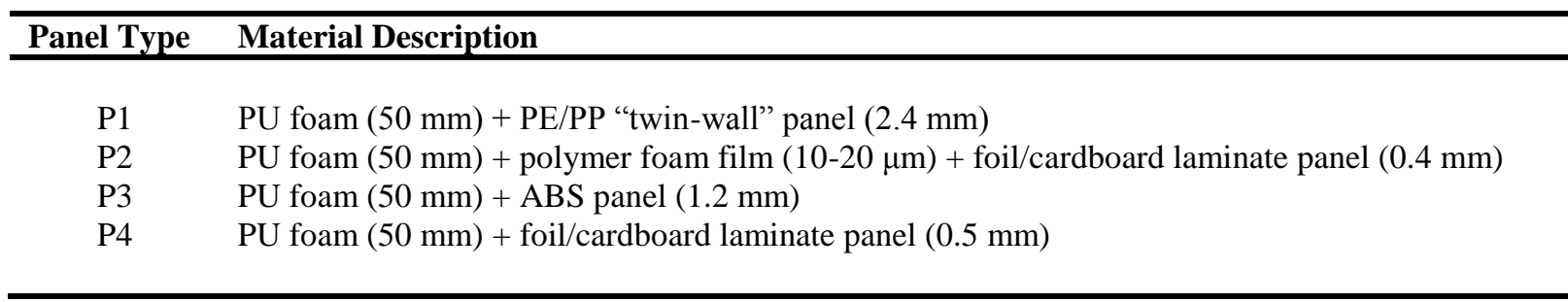

Table 4. Summary of the fridge-freezer back panel materials tested in the fire spread experiments [22].

In order to carry out the tests the thin backing materials (e.g. $2.4 \mathrm{~mm}$ thick "twin-wall") were mounted on top of the polyurethane insulation foam (nominally $50 \mathrm{~mm}$ thick) to form a composite back panel (as would be found in a fridge-freezer). The bottom of the panel was then exposed to a small flame (via a wax taper) for a few seconds to see if it could be ignited. A polyester tensioned thread was mounted $0.5 \mathrm{~m}$ above the ignition point at the bottom edge of the panel. Should flame spread up the panel occur, the failure of the thread would then provide a uniform indication of the time after ignition for the flame to travel this distance. A series of tests were performed using the different back panel specimens, with the back panel open to view. Many of the covering materials rapidly melted away, allowing the underlying foam insulation to become involved. The highest rate of flame spread and fire growth in the tests was observed for the thin polymer foam film and foil/cardboard laminate panel (P2). The majority of the PE/PP "twin-wall" panels tested (P1) also produced high rates of flame spread (Fig. 6). The lowest fire spread rate was observed for the ABS panel (P3), which produced flaming drips early in the test, but did not melt away and tended to protect the foam insulation. The foil/cardboard laminate panel (P4) performed best of all in these tests since it could not be ignited. 


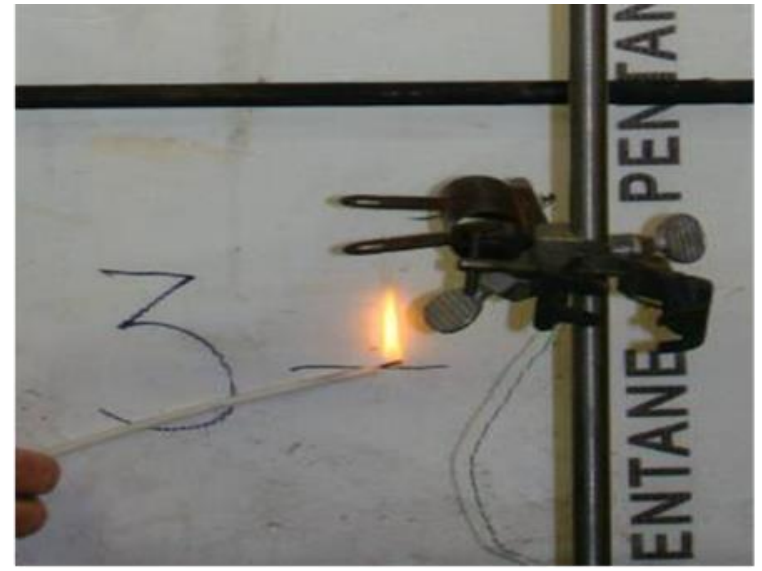

(a)

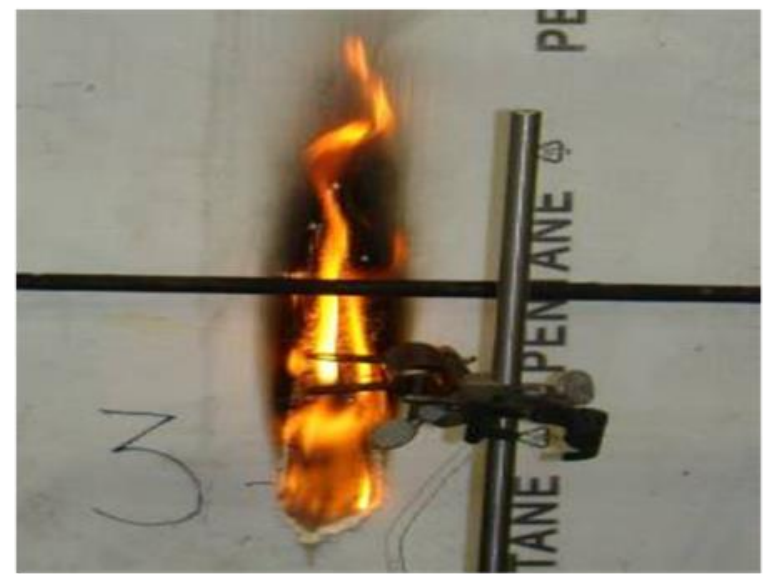

(b)

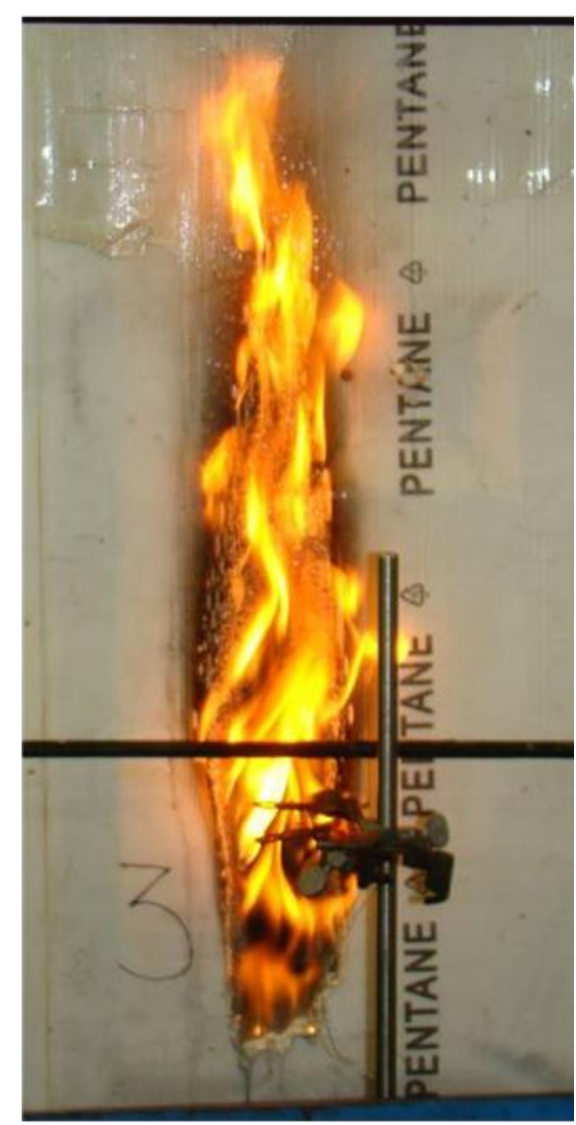

(c)

Fig 6. Burning behaviour of twin-wall backing material; (a) application of ignition source; (b) initial development of flame after $75 \mathrm{~s}$; (c) rapid spread of flame a few seconds later [22].

In everyday operation, the back of a fridge-freezer unit will typically be positioned in close proximity to the surface of a wall. A second set of experimental tests were therefore also performed with the back panel located $50 \mathrm{~mm}$ away from a (non-combustible) wall. The results in this case suggested that the fire spread rate would be further enhanced, due to reradiation of heat from the wall, back to the fire on the back panel, and by creating a chimney effect increasing the airflow drawn into the flue like channel that was formed.

Hietaniemi et. al [10] similarly noted that a significant factor contributing to the growth of the fire in the fridge-freezers VTT tested was the rapid flame spread up the material covering the back of the appliance. They also observed that the development of the fire was inhibited in one of the tests they performed by the presence of a metal plate between the motor space and the freezer. The steel housing was also observed to delay the growth of the fire.

London Fire Brigade, in conjunction with the UK Building Research Establishment (BRE), has also obtained video footage comparing a plastic backed fridge-freezer fire versus a metal backed fridge-freezer fire [23]. The footage clearly illustrates the difference between the two cases, in terms of the growth rate and intensity of the resulting fires (which were started in the compressor compartment at the base of the fridge-freezer). For the plastic 
backed fridge-freezer, the fire spreads rapidly up the rear plastic panel of the unit, becoming well involved after 90 seconds (and had to be extinguished after 150 seconds, before it could overwhelm the test facility). For the metal backed fridge-freezer, the fire is unable to spread up the steel back panel, but instead remains largely restricted to the compressor compartment (and later self-extinguished, after 20 minutes).

\subsection{Polyurethane Foam Insulation Panels}

The early slab constructed internal insulation panels used in the UK have now been replaced by blown hydrocarbon foams - typically rigid polyurethane foam. CFCs used to be used as foam blowing agents, but environmental considerations (damage to the ozone layer) led to production of CFCs being prohibited and the introduction of hydrocarbons, such as cyclopentane, being used as the foam blowing agent [24]. These do not damage the ozone layer, but they are flammable, and hence they further increase the flammability of the insulation. Data from Xiao et al. [25] suggests that cyclopentane comprises around 5\% 0.5 $\mathrm{kg}$ ) of the total mass of foam insulation mass used on a fridge-feezer unit. This is not an insignificant quantity (around ten times the mass of R600a iso-butane used as a refrigerant) and hence it seems plausible that its release could be enhancing the fire development behaviour. The rigid blown foam materials currently in use are officially classified as highly flammable and hazardous waste when sent for disposal. Fire tests have shown that such untreated rigid polyurethane foam insulation offers little resistance to ignition and burns very rapidly, generating high heat release rates, thick smoke and toxic gases. There are also extensive quantities of such materials present in a typical refrigerator creating a high fire load [22]. Hietaniemi et. al [10] also observed that none of the plastic materials used in the appliances they tested were protected by flame retardants.

\section{Why do fridge-freezer fires tend to result in higher levels of damage?}

\section{I Material Composition}

Table 5 presents a comparison of the different domestic white good appliances by the typical mass composition of the materials used in their construction (based on data obtained for typical European appliances taken from EuP Eco Reports [26]). It is evident that both fridge-freezers and tumble dryers are comprised of a higher percentage of plastics almost double that used in washing machines and dishwashers. It can also be seen that the total mass of plastic found in fridge-freezers is significantly higher than for the other types of appliance. The table also provides a breakdown by mass composition for the most common types of plastics used in appliance construction. This would suggest that the main plastics used in fridge-freezers are primarily polystyrene and polyurethane insulation, where-as the main type of plastic used in the other types of appliance is polypropylene. 


\begin{tabular}{|c|c|c|c|c|c|c|c|c|}
\hline \multirow[t]{2}{*}{$\begin{array}{l}\text { Material Mass } \\
\text { Composition }\end{array}$} & \multicolumn{2}{|c|}{$\begin{array}{l}\text { Fridge- } \\
\text { Freezer }\end{array}$} & \multicolumn{2}{|c|}{$\begin{array}{l}\text { Washing } \\
\text { machine }^{2}\end{array}$} & \multicolumn{2}{|c|}{ Dishwasher $^{3}$} & \multicolumn{2}{|c|}{ Tumble Dryer ${ }^{4}$} \\
\hline & kg & $\%$ & kg & $\%$ & kg & $\%$ & kg & $\%$ \\
\hline Ferrous metal & 30.74 & $50 \%$ & 32.36 & $45 \%$ & 27.26 & $57 \%$ & 23.47 & $56 \%$ \\
\hline Non-ferrous & 3.41 & $6 \%$ & 5.31 & $7 \%$ & 1.02 & $2 \%$ & 1.36 & $3 \%$ \\
\hline Plastic (Total) & 19.96 & $32 \%$ & 12.43 & $17 \%$ & 8.34 & $17 \%$ & 13.48 & $32 \%$ \\
\hline ABS & 0.84 & & 1.14 & & 0.75 & & 2.12 & \\
\hline Polypropylene & 1.55 & & 7.93 & & 4.95 & & 7.71 & \\
\hline Polystyrene & 8.90 & & - & & 0.51 & & 0.38 & \\
\hline Polyurethane & 7.93 & & - & & - & & - & \\
\hline Other plastics & 0.74 & & 3.36 & & 2.13 & & 3.27 & \\
\hline Other & 7.65 & $12 \%$ & 22.21 & $31 \%$ & 11.53 & $24 \%$ & 3.84 & $9 \%$ \\
\hline Total & 61.76 & & 72.31 & & 48.15 & & 42.15 & \\
\hline
\end{tabular}

${ }^{1}$ Based on "Cold 7" average model European fridge-freezer LCl data - (Lot 13) Household refrigeration [26].

${ }^{2}$ Based on "WM 5kg" average model European washing machine LCl - (Lot 14) Domestic washing machines and dishwashers [26].

3Based on "DW 12ps" average model European dishwasher LCI - (Lot 14) Domestic washing machines and dishwashers [26]

${ }^{4}$ Based on Base Case model European air condenser tumble dryer Bill of Materials data - (Lot 16) Laundry dryers [26]

Table 5. Comparison of the different white goods appliances by the typical mass composition of materials used in their construction. A breakdown of mass composition for the most common types of plastics used is also shown.

\subsection{Heat Release Rate and Fire Load}

Table 6 shows a comparison of the peak heat release rates that have been observed for the four different types of white goods appliance considered, taken from Babrauskas [27], based upon the results of the fire tests performed by VTT and EFRA. It is clear that, as a result of the greater levels of polyurethane foam insulation material and other plastics being used in their construction, the heat release rate exhibited by fires involving fridge/freezers can be significantly higher than those displayed by the other types of appliance. Thus as a consequence of the fire spread mechanisms identified and high heat release rates evolved, once ignited, fridge/freezer fires are more likely to produce an intense fire which can spread both beyond the appliance and the room of origin and produce greater levels of fire damage than is the case for the other types of white goods appliance.

Table 6 also shows a comparison of the estimated fire load (due to plastics) for each type of white good appliance (estimated using the plastic composition data given in Table 5 and the heat of combustion data for plastics given in [28]). Fridge/freezer have the highest estimated plastic fire loading, followed by tumble dryers. The rankings of the estimated fire 
loadings for each type of appliance also broadly agree with the corresponding peak heat release rates.

\begin{tabular}{lcc}
\hline Appliance type & Peak heat release rate ${ }^{\mathbf{1}}(\mathbf{k W})$ & Estimated plastic fire load $^{\mathbf{2}}(\mathbf{M J})$ \\
\hline & & \\
Fridge/freezer & $852-2125$ & 650 \\
Tumble dryer & 525 & 500 \\
Dishwasher & $345-476$ & 310 \\
Washing machine & $221-431$ & 460
\end{tabular}

${ }^{1}$ Based on heat release rate data from [27]

${ }^{2}$ Estimated using plastic composition data from table 5 and heat of combustion data from [28].

Table 6. Typical peak fire heat release rates observed [27] and estimated fire load due to plastics for the different types of white goods appliance.

\section{Discussion}

The refrigeration appliance is almost unique in its domestic setting as it is one of the few appliances which runs continuously and is not designed to be isolated at night or when left unattended. Hence, it is extremely important that domestic refrigerators be designed and manufactured so that not only the chance of fire is very low, but that should a fire occur it then remains contained within the appliance and not be able to spread. However, the results from sections 3,4 and 5 suggest that not only are there a number of potential ignition mechanisms for fridge/freeze fire which are occurring in practice, but that if ignition should occur then a higher proportion of fires in fridge/freezers spread beyond both the appliance and the room of origin than is the case for the other types of appliance and that they are more likely to result in high levels of fire damage.

\begin{tabular}{lccccc}
\hline Country & $\begin{array}{c}\text { Average } \\
\text { number of } \\
\text { fires } \\
\text { (per year) }\end{array}$ & $\begin{array}{c}\text { Average } \\
\text { number of } \\
\text { casualties } \\
\text { (per year) }\end{array}$ & $\begin{array}{c}\text { Number of } \\
\text { households } \\
\text { with a } \\
\text { refrigerator }\end{array}$ & $\begin{array}{c}\text { Probability of } \\
\text { a fire } \\
\text { (per year) }^{\mathbf{5}}\end{array}$ & $\begin{array}{c}\text { Risk of a fire } \\
\text { casualty } \\
\text { (per year) }\end{array}$ \\
\hline United States & 1710 & 58 & $113,400,000$ & $1.5 \times 10^{-5}$ & $5.1 \times 10^{-7}$ \\
Great Britain & 335 & 88 & $25,362,000$ & $1.3 \times 10^{-5}$ & $3.5 \times 10^{-6}$ \\
\hline
\end{tabular}

\footnotetext{
${ }^{1}$ Based upon an annual average of 2006-2010 home fires, in the US, involving a refrigerator or freezer [5]. ${ }^{2}$ Based upon an annual average of fires and casualties 2009/10 to 2012/13, in residential dwellings in Great Britain, with fridge/freezers given as the source of ignition [1, 30].

${ }^{3}$ Based upon Residential Energy Consumption Survey (RECS) Data, Table HC3.1 Appliances in U.S. Homes, by Housing Unit Type, 2009. [29]

${ }^{4}$ Based upon data for England from ONS Family Spending 2015 - Table A48: Percentage of households with durable goods by UK countries and regions, 2012 to 2014. [18]

${ }^{5}$ Estimate assumes one appliance per household.
}

Table 7. A comparison between the annual average number of fires and casualties, annual probability of fire and risk of fire casualties due to domestic refrigeration appliances in the United States and Great Britain. 


\section{I Comparison between Great Britain and USA}

Table 7 provides a comparison between the annual average number of fires and casualties and the probability of a fire and the risk of a fire casualty (estimated using available data on the number of households having refrigeration appliances $[18,29])$ due to domestic refrigeration appliances in the United States [5] and Great Britain [1,30]. The estimated probability of ignition due to refrigeration appliances is of a similar magnitude for both nations. However, the estimated annual risk of a fire casualty due to refrigeration appliances is approximately seven times higher in Great Britain than in the United States. Similarly, the annual casualty rate (per 1000 fires) due to domestic refrigeration fires, is nearly eight times higher in Great Britain than in the United States (see Fig. 7). This data suggests that a significant difference exits between the two countries with regard to the occurrence of severe refrigeration fires.

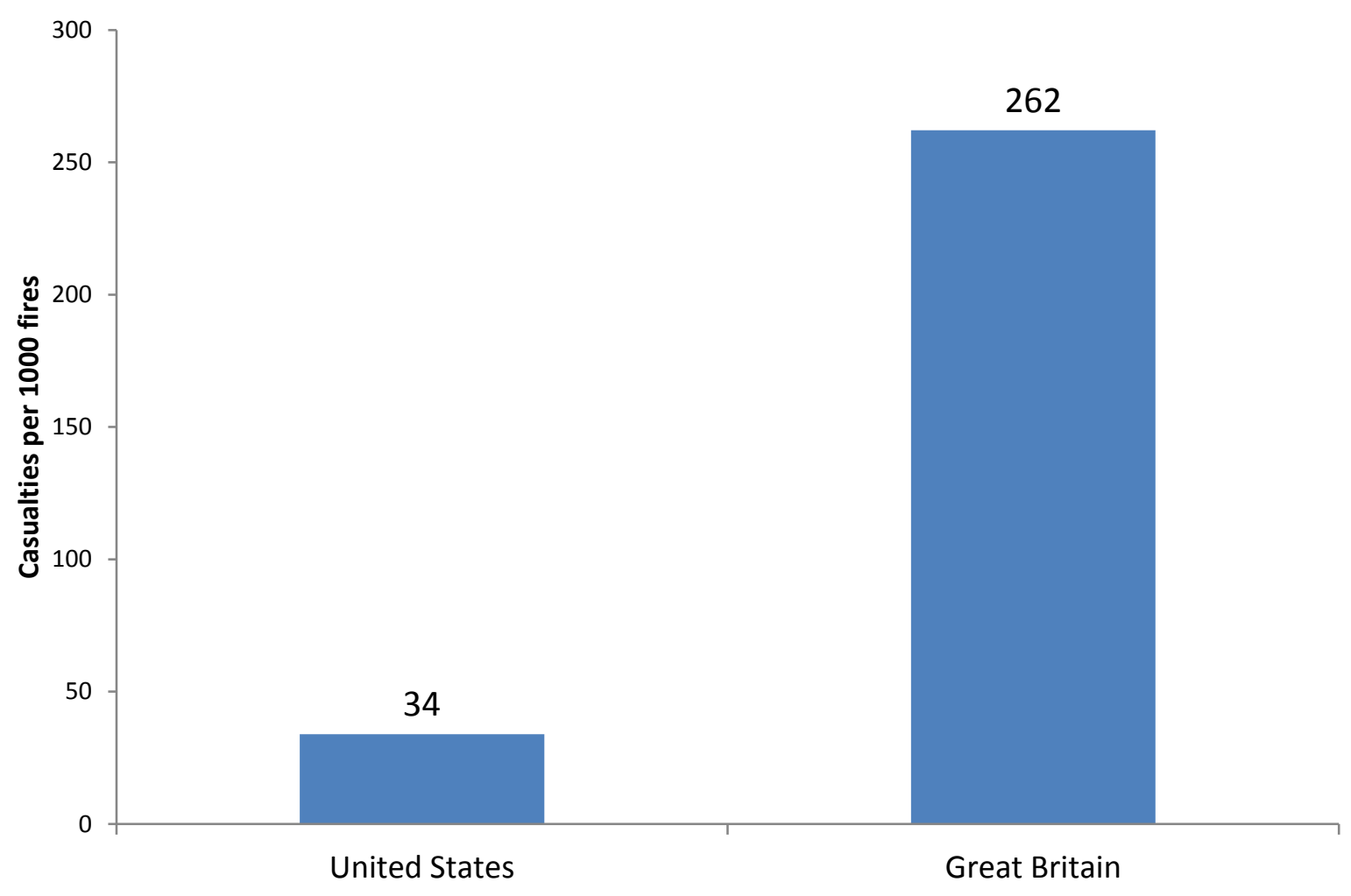

Fig 7. A comparison between the fire casualty rate (per 1000 fires) due to domestic refrigeration fires for USA and Great Britain.

A comparison between the two countries suggests that a number of significant differences in refrigerator appliance design and construction have arisen. For example refrigerators in the USA still have a largely steel housing construction (casing and back wall) and use metal drip trays. They also tend to use more fault tolerant components that are less likely to fail and act as sources of ignition, and have a policy of surrounding potential ignition sources in metal box containments, isolating then from other flammable items. For example, in the USA manufacturers have tended to use compressor motor capacitors with a higher (S2) 
safety class that are more fault tolerant. In accordance with IEC 60252-1 [31], the four the classes of safety protection for a motor capacitor are defined as: SO (formerly PO) indicates that the capacitor has no specific failure protection; S1 (formerly P1) indicates the capacitor may fail in either open circuit or short circuit; S2 (formerly P2) indicates the capacitor has been designed to fail in the open circuit mode only; and S3 indicates that the capacitor is of segmented film construction (designed to enhance self-healing of dielectric breakdown and limit the area of damage). Thus, in the USA, protective S2 safety class capacitors are specified which have a "fail safe" pressure sensitive design. This is intended to expand and disconnect the electrical supply before the pressure reaches a point where the capacitor could rupture or explode, and eject the burning capacitor contents, hence reducing the likelihood of a failed compressor motor capacitor acting as an ignition source.

In the UK (and EU) the only real driver for improving the fire safety design of appliances is to legislate through changes to standards. The failure of electrical components is always a possibility - the resulting fire growth following a failure is also predictable. The solution is often financially achievable, but it falls to standards to determine and set the changes. In contrast, in the USA design and regulation of refrigerators is driven by the insurance industry (via the Underwriters Laboratory) and threat of litigation. This difference in regulatory system would appear to be the most likely explanation for the differences in refrigerator appliance design and construction that are seen between the UK and USA.

\subsection{Recommendations for reducing the risk}

Consideration of the potential ignition sources and escalation mechanisms observed during LFB fire investigations and the differences in UK and USA fridge/freezer construction suggests that the following recommendations be followed to reduce the likelihood and severity of domestic fridge/freezer fires:

\subsubsection{Avoidance of plastics in housings}

UK and European fridge/freezer appliances tend to employ plastic housings and use substantial quantities of polyurethane foam insulation. Consequently, should a fire occur, it can burn with a high HRR and will be more likely to spread beyond the appliance and the room of origin and cause a significant level of damage (see sections 4 and 5). Conversely, in North America the housings used in fridge/freezers are made from steel and so are likely to inhibit flame spread, delaying the involvement of the foam insulation and act so as to contain a fire, should ignition occur.

From a fire safety standpoint, it is recommended that the usage of combustible plastics in appliance housings should be avoided - ideally the entire housing should be constructed from steel or other fire proof material to contain the fire and prevent or delay flame spread to the foam insulation material. Often the exterior front and sides of the housing in European appliances will be constructed from metal, but the back will be plastic ("twinwall") or cardboard. The rear wall covering of a fridge/freezer is particularly vulnerable to upward fire spread should ignition occur, since the location of the compressor housing at the rear of the bottom of the fridge/freezer makes this the likely location of an ignition source. It is therefore particularly important that a metal plate or other non-combustible 
covering should be used at the back of the appliance to prevent fire spread. The backing plate covering should be well sealed, with no gaps or penetrations which could allow flame spread to the interior insulation material. It is also recommended that a simple light weight metal plate be fitted to completely separate the compressor motor and housing from the rest of the unit to prevent fire spread.

\subsubsection{Containing potential ignition sources in metal boxes}

As shown in section 3, internal components within the appliance, such as capacitors, can fail and act as ignition sources. It is recommended that such potential ignition sources should be isolated from flammable foam insulation material, by locating them behind fire resisting barriers and in metal fire resisting boxes to prevent fire spread to the insulation foam should failure occur.

\subsubsection{Measures to limit the flammability/combustibility of foam insulation materials}

Based upon environmental and cost considerations the use of polyurethane foam insulation materials in refrigeration appliances is highly attractive to manufacturers, since they can employ large quantities of foam insulation to minimise heat transfer and cooling losses and maximise the efficiency of the appliance, helping to meet targets for reducing climate change. However, as discussed in section 5.3, this foam insulation is also highly flammable, producing very high heat release rates, toxic combustion products and promoting rapid fire growth and spread. The introduction of measures to limit the flammability and combustibility of the foam insulation materials used in fridge/freezers are therefore required.

Flame retardants could be added to the insulation foam or applied to insulation surfaces to inhibit ignition and suppress flame spread to help achieve this goal. However, the usage of traditional halogen based flame retardants is highly contentious. There is a growing body of evidence to suggest that: (i) by interfering with the efficiency of the combustion process they can serve to significantly increase the yield and toxicity of carbon monoxide, smoke and other products of incomplete combustion produced [32]; (ii) they are only effective against small ignition sources at the low loadings typically applied in commercial foam plastic insulation [27]; and (iii) they can have an adverse impact on human health and the environment - for example they are a suspected cause for the super-abundant incidence of cancer in firefighters and can form dioxins (e.g. during incineration for disposal) which have been linked to a number of serious health effects and have been shown to accumulate in the food chain [33-35]. There is therefore a need for the development of a new generation of safer and environmentally friendly, "halogen-free", flame retardants for use with foam insulation to overcome these limitations and harmful effects. For example, Costes et al. [36] discuss recent progress with regards to the development of efficient green flame retardant additives based on bio-based compounds, which upon combustion readily form a stable surface char layer that acts as an efficient thermal barrier protecting the underlying material. 


\section{Conclusion}

The generic reasons for the cause and spread of domestic refrigeration fires have been examined, using information obtained from the analysis of fire data sets available in Great Britain (for both London and England) and on the basis of fire investigations carried out in London.

The results suggest that although fridge/freezers might be expected to have a higher fire incidence rate, since they are powered and actively functioning a much larger fraction of the time than the other types of white goods appliances, they actually exhibited the lowest probability of fire occurrence $\left(1.5 \times 10^{-5}\right.$ per year $)$ - around half that found for both dishwashers and tumble dryers $\left(3.1 \times 10^{-5}\right.$ per year).

However, analysis of these incidents also suggests that, once ignition occurs, fires caused by fridge/freezers are more likely to exhibit a higher degree of fire spread and produce greater levels of damage than other types of white goods appliance (washing machine, dishwasher or tumble dryer). Nearly $80 \%$ of fires with fridge/freezers as the source of ignition, spread (caused fire damage) beyond the first item involved, whilst almost $40 \%$ spread beyond the room of origin. Fires involving fridge/freezers also displayed a far higher casualty rate per fire (335 casualties per 1000 fires) than was found for the other types of appliance.

The reason for the severity of these fridge/freezer fires can be attributed to a combination of components that can fail and act as an ignition source, located in close proximity to an extensive source of flammable plastics and insulation material, used in the appliance housing, which can burn readily and spread the fire, producing very high heat release rates. Such incidents have highlighted the vulnerability of modern construction methods and have produced some of the most serious fires recorded in residential dwellings in Great Britain.

A number of common failure modes leading to ignition in domestic refrigeration fires have been identified: (i) starter relay failures; (ii) PTC switch failures; (iii) mechanical defrost switch failures; (iv) capacitor failures; (v) solenoid valve failures; and (vi) cut-out switch failures in integrated appliances. Specific fire escalation and spread mechanisms have also been identified: plastic drip trays, "twin-wall" backing materials and polyurethane foam insulation panels.

There is also evidence to suggest that the severity of refrigeration fires in Great Britain is significantly higher than in the USA. Based upon information obtained from LFB fridge and freezer fire investigations, and a comparison between the design and construction of refrigeration appliances used in Great Britain and USA, a number of recommendations have been made which could be used to significantly reduce the risk of a serious fire e.g. avoiding the usage of plastics in appliance housings and in particular employing a metal/noncombustible covering at the back of fridge and freezer appliances. 


\section{References}

[1] Department for Communities and Local Government, Fire Statistics, Great Britain, (2005 $-2015)$.

[2] BBC News: "Neasden family fire deaths: 'Freezer failure' to blame", 24 October 2012. http://www.bbc.co.uk/news/uk-england-london-20076214 (accessed 03.07.18)

[3] https://www.grenfelltowerinquiry.org.uk/evidence/professor-niamh-nic-daeids-expertreport (accessed 03.07.18).

[4] LFEPA, Fires in White Goods and Product Recalls: Actions for LFB in 2016/17, Report FEP 2572, March 2016. http://moderngov.london-fire.gov.uk/mgconvert2pdf.aspx?id=5021 (accessed 03.07.18).

[5] J.R. Hall, Home structure fires involving kitchen equipment other than cooking equipment, National Fire Protection Association, (2012).

[6] W. Yang, S. Ling, S. Mo, D. Liang and Y. Wang, Research of Trace Analysis and Investigation Method for Refrigerator-caused Fire. Procedia Engineering, 52 (2013) 526-531.

[7] NFPA, NFPA 921 - Guide for Fire and Explosion Investigations. National Fire Protection Association, Quincy, USA, 2014.

[8] J. D. DeHaan, Kirk's Fire Investigation, $5^{\text {th }}$ Edition, Pearson/Brady, New Jersey, USA, 2002.

[9] G.E. Gorbett, B.J. Meacham, C.B. Wood and N.A. Dembsey, Use of damage in fire investigation: a review of fire patterns analysis, research and future direction. Fire Science Reviews, 4 (2015) 1-35.

[10] J. Hietaniemi, J. Mangs and T. Hakkarainen, Burning of Electrical Household Appliances - An Experimental Study, Research Notes 2084, VTT Building Technology, 2001.

[11] D. Drysdale, An Introduction to Fire Dynamics, $3^{\text {rd }}$ edn. Wiley, Chichester, UK, 2011.

[12] A. Beard and S. Goebelbecker, Fire Behaviour of Household Appliances towards External Ignition, European Flame Retardants Association (EFRA), 2007. https://flameretardants-online.com/images/itempics/8/8/1/item_18188_pdf_1.pdf (accessed 03.07.18).

[13] Office of the Deputy Prime Minister, Fire Statistics (UK) 2002-2004, 3 year average (2004).

[14] P.G. Holborn, P.F. Nolan, J. Golt, N. Townsend, Fires in workplace premises, Fire Saf. J., 37 (2002) 303-327. 
[15] P.G. Holborn, P.F. Nolan, J. Golt, An analysis of fatal unintentional fires investigated by London Fire Brigade between 1996 and 2000, Fire Saf. J., 38 (2003) 1-42.

[16] P.G. Holborn, P.F. Nolan, J. Golt, An analysis of fire sizes, fire growth rates and times between events using data from fire investigations, Fire Saf. J., 39 (2004) 481-524.

[17] Home Office, Publishing Incident Recording System, data on the fire and rescue service at an Incident Level: Domestic Appliance Fires Dataset Guidance, Home Office, OGL, UK, 2017. https://www.gov.uk/government/statistical-data-sets/fire-statistics-datatables\#incident-level-datasets (accessed 03.07.18).

[18] Office for National Statistics, Family Spending 2015, Table A48: Percentage of households with durable goods by UK countries and regions, 2012 to 2014.

[19] D. Kim, W. Um, H. Kim, Electrical breakdown of the positive temperature coefficient of resistivity barium titanate ceramics. J. Mater. Res., 11, (1996) 2002-2008.

[20] R.R. Fullwood and R.E. Hall, Probabilistic risk assessment in the nuclear power industry. Pergamon Press, UK, 1988.

[21] G. Ramachandran and D. Charters, Quantitative Risk Assessment in Fire Safety, Spon Press, London, 2011.

[22] A. Vaughan-Davies, Refrigeration Appliances - Ignitability, Flammability and Toxicity of refrigeration appliance back panel plastic and its insulation when involved in fire, London Fire Brigade Fire Investigation Research Report, (2012).

[23] London Fire Brigade, Video footage of fridge-freezer fire tests performed at BRE https://www.london-fire.gov.uk/news/2015-news/fridge-freezer-delay-putting-lives-at-risk/ (accessed 03.07.18).

[24] K. Nistitani and M. Itoh, Product innovation in response to environmental standards and competitive advantage: a hedonic analysis of refrigerators in the Japanese retail market, Journal of Cleaner Production, 113 (2016), 873-883.

[25] R. Xiao, Y. Zhang, X. Liu and Z. Yuan, A life-cycle assessment of household refrigerators in China, Journal of Cleaner Production, 95 (2015), 301-310.

[26] EuP Eco Reports - https://www.eup-network.de/product-groups/preparatorystudies/completed/ (accessed 26.10.18).

[27] V. Babrauskas, Chapter 26: Heat Release Rates, in SFPE Handbook of Fire Protection Engineering, Fifth Edition, M.J. Hurley (Ed), Springer, 2016.

[28] Appendix Table A.31, in SFPE Handbook of Fire Protection Engineering, Fifth Edition, M.J. Hurley (Ed), Springer, 2016. 
[29] U.S. Energy Information Administration, 2009 Residential Energy Consumption Survey (RECS) Data, Table HC3.1 Appliances in U.S. Homes, by Housing Unit Type, 2009. https://www.eia.gov/consumption/residential/data/2009/ (accessed 03.07.18).

[30] Department for Communities and Local Government, Fire Statistics Great Britain 20122013: casualties from accidental fires. https://www.gov.uk/government/statistics/firestatistics-great-britain-2012-to-2013 (accessed 03.07.18).

[31] IEC 60252-1:2010+A1:2013, AC motor capacitors. General. Performance, testing and rating. Safety requirements. Guidance for installation and operation, IEC, 2013.

[32] A.A. Stec, Fire toxicity - The elephant in the room? Fire Saf. J., 91 (2017) 79-90.

[33] B. Shen, T.P. Whitehead, S. McNeel, F.R. Brown, J. Dhaliwal, R. Das, L. Israel, J. Park, M. Petreas, High levels of polybrominated diphenyl ethers in vacuum cleaner dust from California fire stations, Env. Sci. Tech. 49, (2015), 4988-4994.

[34] A. Cordner, Firefighters and flame retardant activism, New Solutions, 24 (2015) 511534.

[35] V. Babrauskas, D. Lucas, D. Eisenberg, V. Singla, M. Dedeo, A. Blum, Flame Retardants in Building Insulation: A Case for Re-evaluating Building Codes, Building Research \& Information, 40 (2012) 738-755.

[36] L. Costes, F. Laoutid, S. Brohez, P. Dubois, Bio-based flame retardants: When nature meets fire protection, Materials Science and Engineering R, 117 (2017) 1-25. 